\title{
Hiperalgesia asociada al tratamiento con opioides
}

\author{
A. Gil Martín, M. Moreno García, J. Sánchez-Rubio Ferrández y T. Molina García \\ Servicio de Farmacia. Hospital Universitario de Getafe. Madrid
}

Gil Martín A, Moreno García M, Sánchez-Rubio Ferrández J, Molina García T. Hiperalgesia asociada al tratamiento con opioides. Rev Soc Esp Dolor 2014; 21(5): 259-269.

\begin{abstract}
Opioid induced hyperalgesia is a paradoxical reaction characterized by an enhanced perception of pain related to the use of these drugs in the absence of disease progression or withdrawal syndrome. In contrast to cases of tolerance, defined as the loss of analgesic potency during prolonged use of opioids, no improvement is seen with dose escalation. Opioid induced hyperalgesia could be manifested in the context of maintenance dosing and withdrawal, at very high or escalating doses, and at ultra-low doses. To establish a differential diagnosis is important to consider that increasing the dose may produce a temporary improvement in patients with tolerance but not in those who develop hyperalgesia.

Pathogenesis of this phenomenon is not well defined, but there are several experimental studies in animal models and in humans that have shown that hyperalgesia is not triggered by a single factor. Proposed mechanisms include: NMDA receptor mediation, modulation by the calcium/calmodulin protein kinase, the increase in the number of nociceptors or excitatory neurotransmitters release. There are different treatment strategies available, such as the reduction in the dose of opioid used, opioid rotation or association of other analgesic. Other options are NMDA receptor antagonists or combination therapy with COX-2 inhibitors. In this paper we review recent advances in the understanding of the underlying mechanisms, clinical studies and available treatment strategies.
\end{abstract}

Key words: Hyperalgesia. Opioid. Nociception.

\section{RESUMEN}

La hiperalgesia inducida por opioides es una reacción paradójica caracterizada por una percepción intensificada de dolor relacionada con el uso de estos medicamentos en ausencia de progresión de la enfermedad o de síndrome de retirada. A diferencia de los casos de tolerancia, definida como pérdida de potencia analgésica durante el uso prolongado de opioides, no se produce mejoría con el escalado de dosis. La hiperalgesia inducida por opioides se ha manifestado en pacientes con dosis de mantenimiento y retirada, pacientes con dosis elevadas o escalado de dosis y pacientes con dosis ultra bajas. Para establecer un diagnóstico diferencial es importante tener en cuenta que un incremento de dosis puede producir una mejoría temporal en pacientes con tolerancia pero no en los que han desarrollado hiperalgesia. La prevalencia de dicho fenómeno es desconocida, pero puede ser más frecuente de lo esperado y muchas veces no reconocido. El mecanismo subyacente no está bien definido, pero existen diversos estudios experimentales tanto en modelos animales como en humanos en los que se observa que la hiperalgesia no está desencadenada por un único factor, sino que son muchos los implicados. Entre los mecanismos propuestos destacan: la mediación del receptor NMDA (N-metil-D-aspartato) activado por la liberación presináptica de glutamato, la modulación por la proteína-kinasa de calcio/calmodulina, el aumento en el número de nociceptores o la liberación de neurotransmisores excitadores. Se han realizado diversos estudios para describir la expresión y la relevancia de la hiperalgesia inducida por opioides en distintos grupos de pacientes: ex-adictos a opioides en tratamiento de mantenimiento con metadona, en exposición perioperatoria, en voluntarios sanos o en dolor crónico. Existen diferentes estrategias de tratamiento disponibles; entre las más aceptadas se encuentra la reducción en la dosis del opioide utilizado, la rotación del opioide o la asociación al tratamiento de otro tipo de analgésico. Otras opciones son los antagonistas del receptor NMDA o la terapia combinada con los inhibidores de la COX-2. En el presente trabajo se revisan los avances recientes en el conocimiento de los mecanismos subyacentes que la producen, los estudios clínicos realizados así como las diferentes estrategias de tratamiento disponibles.

Palabras clave: Hiperalgesia. Opioide. Nocicepción. 


\section{INTRODUCCIÓN}

Los analgésicos opioides se han utilizado durante siglos para el tratamiento del dolor moderado a severo y constituyen el pilar fundamental de la terapia del dolor crónico, especialmente en pacientes con cáncer, aunque actualmente varias sociedades científicas y guías de práctica clínica recomiendan su uso también en el dolor crónico no canceroso $(1,2)$. La utilización de estos fármacos se ha visto incrementada en las últimas décadas (3), sin embargo, su consumo es variable entre los diferentes países con prevalencias de uso que varían entre el 4 y el $30 \%$ de la población (4).

En ocasiones, el tratamiento con estos fármacos falla, haciendo surgir cuestiones acerca de la capacidad para mantener la eficacia analgésica en el tiempo así como sobre qué mecanismos subyacentes están implicados en el fracaso terapéutico (5).

Por otro lado, los efectos adversos producidos por fármacos opioides son frecuentes, afectando al $77 \%$ de pacientes con dolor crónico no canceroso, aunque los más comunes son de carácter leve, como el desarrollo de náuseas, estreñimiento y somnolencia. Otros efectos adversos que pueden aparecer son: alteraciones del sueño, fatiga, vómitos, picor, ansiedad y depresión, cambios endocrinos, boca seca, depresión respiratoria, deficiencia neurocognitiva y efectos cardiovasculares como prolongación del intervalo QT (6).

En cualquier caso la incidencia de reacciones adversas es variable en función del medicamento y las dosis empleadas, siendo menor cuando se usan dosis bajas o moderadas, incluso cuando se combinan con benzodiacepinas o antidepresivos (7).

El desarrollo de tolerancia y dependencia tras el uso prolongado de opioides es un efecto claramente establecido en este grupo farmacológico.

La tolerancia se define como la pérdida de potencia analgésica durante el uso prolongado de opioides que conduce a un incremento continuo de los requerimientos de dosis y una disminución de la eficacia del tratamiento en el tiempo, es decir, se necesita un aumento de dosis para conseguir el mismo efecto farmacológico (8).

La dependencia se caracteriza por la aparición de síndrome de retirada cuando el medicamento se interrumpe bruscamente, cuando la dosis se reduce muy rápidamente o cuando se administran antagonistas (9).

La hiperalgesia inducida por opioides (HIO) es un resultado no esperado de la terapia con estos fármacos que se caracteriza por una percepción intensificada de dolor relacionada con el uso del medicamento en ausencia de progresión de la enfermedad o de síndrome de retirada. Fue descrita por primera vez en 1870 por Albutt (10). Esta respuesta paradójica se manifiesta como una pérdida de la eficacia analgésica, en ausencia de un nuevo daño tisular o empeoramiento de la enfermedad de base, en general en pacientes en tratamiento crónico con medicamentos opioides que, a diferencia de la tolerancia, empeora con el escalado de las dosis del fármaco (11). Es por tanto una reducción del umbral del dolor respecto a la situación basal creando un estado de hiperalgesia tras una exposición prolongada a opioides (12). Sin embargo, en ocasiones puede aparecer también tras cortos periodos de tratamiento.

Este dolor atípico parece no estar relacionado con los estímulos nociceptivos originales y se caracteriza porque el dolor se hace más difuso, cualitativamente menos definido y con una distribución espacial más amplia (13).

En la hiperalgesia se produce una mayor sensibilidad al estímulo doloroso mientras que en la alodinia, en sentido estricto, la hipersensibilidad produce sensación de dolor con estímulos inicialmente no dolorosos (Fig. 1).

La HIO se ha definido en 3 diferentes contextos: pacientes con dosis de mantenimiento y retirada, pacientes con dosis elevadas o escalado de dosis y pacientes con dosis ultra bajas (14). Este aspecto del tratamiento con opioides es en ocasiones pasado por alto y sin embargo es de gran importancia ya que puede complicar el curso clínico del tratamiento del dolor.

En el presente trabajo se revisan los avances recientes en el conocimiento de los mecanismos subyacentes que la producen, los estudios clínicos realizados para su caracterización así como las diferentes estrategias de tratamiento disponibles.

\section{MATERIAL Y MÉTODOS}

Se realizó una revisión sistemática de artículos publicados en los últimos 5 años (2008-2013) relacionados con la HIO mediante búsqueda en MEDLINE utilizando las palabras clave "hyperalgesia, opioid, allodynia".

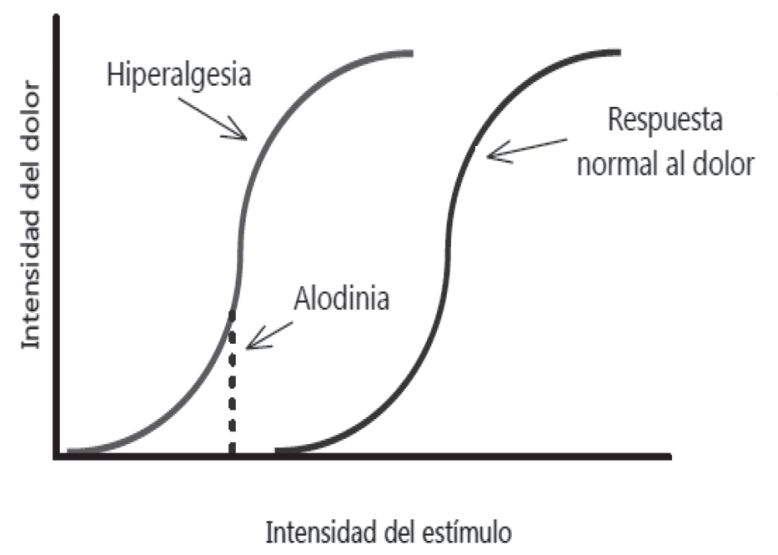

Fig. 1. Hiperalgesia, alodinia y sensibilidad normal al dolor (adaptado de Richebe et al.) (9). 


\section{RESULTADOS}

\section{Diagnóstico diferencial}

El reconocimiento de la $\mathrm{HIO}$ es un reto clínico de difícil respuesta. Se han realizado algunas aproximaciones diagnósticas a nivel experimental con el objetivo de determinar el umbral y la tolerancia al dolor tras estímulos térmicos y mecánicos - Quantitative Sensory Testing (QST) o Prueba cuantitativa sensorial — o solo mediante frío (cold pressor test). Sin embargo su aplicación clínica es reducida.

En general, puede sospecharse del desarrollo de HIO en pacientes en tratamiento con opioides que experimentan un empeoramiento del dolor. Sin embargo, debe tenerse en cuenta que esta situación puede deberse a diferentes circunstancias, como el desarrollo de tolerancia al tratamiento, la dependencia en pacientes adictos o el empeoramiento de la enfermedad de base. En cualquier caso, la principal diferencia radica en que el incremento de dosis puede producir una mejoría, al menos temporal, en todas las situaciones salvo en la HIO (11).

\section{Epidemiología}

La prevalencia de la HIO es desconocida. Existen escasos estudios clínicos que hayan explorado la HIO y por otro lado, este efecto puede depender de las características del opioide utilizado y del paciente. Según algunos autores, aunque raro, puede ser más frecuente de lo esperado y muchas veces no reconocido (15).

\section{Mecanismo}

El mecanismo de la HIO ha sido explorado con frecuencia tanto en ensayos de investigación básica como en humanos. La HIO no está desencadenada por un único factor, sino que son muchos los implicados y propuestos, incluyendo factores genéticos. La HIO, tolerancia y dolor neuropático pueden compartir mecanismos comunes en un cierto nivel aunque sean fenómenos distintos. Los mecanismos descritos más importantes son los que se exponen a continuación.

\section{Calcio/calmodulina proteína kinasa II (CaMKIIa)}

Es una serina/treonina proteína kinasa regulada por el complejo calcio-calmodulina. La CaMKII $\alpha$ está involucrada en varias cascadas de señalización celular y es mediadora importante en los procesos de aprendizaje y memoria. En un estudio en ratones a los cuales se les había inducido previamente un estado de hiperalgesia y alodinia, la admi- nistración de la molécula KN93 (inhibidor de CaMKII $\alpha$ ) a dosis elevadas, conseguía a los 30 minutos iniciar la reversión del estado, alcanzando el pico de acción a las 2 horas de la administración. Por otro lado, la utilización de RNA de interferencia para disminuir la expresión de CaMKII $\alpha$ en la médula espinal llegó a revertir la hiperalgesia, reforzando la idea de que esta vía juega un papel crucial en el desarrollo de la HIO (16).

\section{Receptores NMDA (N-metil-D-aspartato)}

Es el mecanismo más ampliamente estudiado. Las señales dolorosas se propagan a lo largo de la médula espinal por el neurotransmisor glutamatérgico a través del subtipo NMDA del receptor de glutamato. Estos receptores están localizados postsinápticamente y extrasinápticamente en la membrana de las neuronas del asta dorsal y son activados por la liberación presináptica de glutamato desde las terminaciones nerviosas de las células de ganglios de la raíz dorsal despolarizadas por un estímulo doloroso mecánico o químico (17). Pruebas funcionales muestran cambios metabólicos en el cerebro y en las concentraciones de glutamato y/o GABA en el córtex somatosensorial en pacientes con hiperalgesia (18).

La nocicepción inducida por opioides viene acompañada de la sensibilización de neuronas espinales. Este mecanismo está mediado por el sistema central glutamatérgico vía receptor NMDA y se ha demostrado que se invierte con antagonistas del mismo como la molécula MK801. Añadido a eso, la administración crónica de morfina provoca la obtención de niveles elevados de péptidos pronociceptivos CGRP (péptido relacionado con el gen de calcitonina) y SP (sustancia P) dentro del ganglio de la raíz dorsal (19).

Según Zhao y cols., tras la exposición a opioides, en las láminas I y II de las neuronas espinales se produce un incremento duradero, a través de la activación presináptica de receptores NMDA, de liberación de glutamato desde las neuronas aferentes primarias nociceptivas (20). En otro estudio se demostró que la exposición a dosis de 4,6 , y $8 \mathrm{nM}$ de remifentanilo, pero no 1,2 y $10 \mathrm{nM}$ causan un incremento significativo de la respuesta mediada por NMDA; así se plantea la posibilidad de que el desarrollo de la HIO sea concentración dependiente y se produzca a concentraciones clínicamente relevantes. Esta respuesta fue atenuada con la aplicación de antagonistas de receptores opioides $\mu$ y $\delta$, sugiriendo que la activación por remifentanilo de ambos tipos de receptores es necesaria para el incremento de la respuesta mediada por NMDA. Sin embargo, la exposición a los agonistas selectivos $\delta$ opioides DPDPE (D-Penicilamina(2,5)-encefalina) y deltorfina II, fueron capaces de inducir por sí solos, aumentos en la respuesta mediada por receptores NMDA (17). 


\section{Aumento del número de nociceptores}

En el organismo existen una clase especial de fibras aferentes que son insensibles y requieren de daño o inflamación para excitarse. Dichas fibras representan un elevado porcentaje de la población de nociceptores cutáneos, por lo que su activación amplificaría la transmisión total de manera significativa, mandando una señal de daño al SNC. Hogan y cols. en un estudio con ratones en tratamiento crónico con morfina $v s$. solución salina señalaron que la prevalencia de nociceptores era mayor en el primer grupo frente al segundo. Dicho hallazgo fue atribuido al aumento de la activación de fibras insensibles, mandando una señal falsa de daño al SNC y con ello contribuyendo a la generación de HIO (21). El receptor de potencial transitorio V1 (TRPV1) es un canal iónico no selectivo activado por estímulos físicos y químicos que se encuentra en el SNC y SNP involucrados en la transmisión y modulación del dolor vía señales MAPK (proteínas kinasas activadas por mitógenos). Chen observó que la expresión de dicho receptor en médula espinal, nervio ciático y raíz del ganglio dorsal, estaba aumentada en ratas con tratamiento crónico de morfina (21). Por el contrario, si se administraba la molécula SB366791 (antagonista TRPV1), la hiperalgesia quedaba suprimida (22). Vardanyan y cols. describieron que, tras la administración sostenida de morfina, los ratones mutados carentes de TRPV1 no desarrollaban hiperalgesia térmica ni mecánica. Por otro lado la administración de un antagonista TRPV1 (AMG0347) en ratones no mutados revirtió la HIO (23).

Wilson y cols. determinaron que muchas neuronas nociceptivas expresan receptores funcionales para ciertas citoquinas con la administración de morfina, y, por ejemplo, se induce la señal SDF1 (citoquina) vía receptor CXCR4 cambiando el balance entre la analgesia e hiperalgesia mediada por opioide. La HIO puede ser revertida de forma transitoria con la administración de un antagonista selectivo de los receptores CXCR4. El incremento en la activación de SDF1/CXCR4 podría ser el resultado de la mejora en la liberación del SDF1 neuronal, cuya expresión está activada bajo estas condiciones, o por algunos efectos postsinápticos de la morfina que producen la desensibilización de CRCX4 en respuesta a la liberación de SDF1 (24).

\section{Aumento y liberación de neurotransmisores excitadores}

El tratamiento crónico con morfina libera un exceso de producción de citokinas que aumenta la sensibilización nociceptiva y una regulación al alza en la producción y liberación de neurotransmisores en las fibras nerviosas aferentes. Las citokinas que más se han relacionado con la HIO son la IL-1 $\beta$, G-CSF y CK (25).
Potenciación sináptica a largo plazo (LTP)

Los opioides se unen a los receptores $\mu$ opioides (MOR) presentes en las fibras espinales terminales presinápticas nociceptivas y en las neuronas postsinápticas en el asta dorsal de la médula espinal. Los MOR se encuentran también en neuronas de varias áreas cerebrales, incluyendo la médula rostral ventromedial (MRV), que envían proyecciones descendentes a la médula espinal. Los agonistas de MOR podrían activar las vías descendentes que modulan la nocicepción espinal. Heinl y cols. registraron que, tras sucesivos días de administración de opioides, la analgesia inicial se tradujo en HIO. En un primer momento se produjo un descenso de la activación sinérgica de las fibras-C, que fue transformándose poco a poco, hasta convertirse en un aumento de la activación de las fibras-C con la administración continua de opioides (26).

\section{Dinorfinas espinales}

El incremento de la actividad del péptido activador neurotransmisor colecistoquinina en la MRV, activa las vías espinales que a su vez, activan las dinorfinas espinales y consecuentemente se desarrollan entradas nociceptivas a nivel espinal (18).

\section{Influencia genética}

La acetilación de las histonas está controlada por los sistemas enzimáticos de histona acetiltransferasa (HAT) e histona desacetilasa (HDAC) de manera recíproca e influye en el desarrollo de tolerancia a sustancias de abuso como cocaína y alcohol. Un mecanismo epigenético asociado a la prolongación sustancial de la HIO ha sido el expuesto por Lian y cols. en un estudio donde se determinaba si un inhibidor de HAT (curcumina) o un inhibidor de HDAC (SAHA: ácido hidroxámico suberoilanilida) afectaba a la HIO por tratamiento crónico con morfina. En el caso de curcumina, la HIO era prevenida, mientras que con SAHA se aumentaba la sensibilidad térmica y mecánica. Cuando ambos inhibidores se administraban en ratones no tratados con morfina, no se veían afectados los umbrales de nocicepción (27).

\section{Otros mecanismos}

- Bioactivación de los metabolitos glucurónidos excitatorios procedentes de los opioides consumidos: la morfina está sujeta a glucuronidación hepática y en última instancia se produce morfina-6 $6 \beta$-glucurónido y morfina-3ß-glucurónido (M3G). La inyección de 
M3G en ratones vía cerebroventricular, intratecal o sistémica aumentan la nocicepción. Más importante es que M3G no tiene afinidad apreciable por ningún subtipo de receptor opioide y sus efectos neuroexcitatorios no son bloqueados por al antagonista de opioides naloxona. El fentanilo, sin embargo, no se metaboliza por glucoronidación y también causa hiperalgesia independiente de la actividad del receptor opioide (28).

- El receptor de serotonina 5-HT3 está constituido por 5 monómeros que forman una estructura permeable a cationes. Dicho receptor se expresa en cerebro, médula espinal y tejidos ganglionares de la raíz dorsal y está implicado en la aparición de distintos síntomas como náuseas y vómitos, dolor y ansiedad. Liang en un estudio con roedores vio que, tras el desarrollo de HIO por administración crónica de morfina y la administración de un antagonista selectivo del receptor 5-HT3 (ondansetron), la HIO se revertía de manera significativa en las primeras horas. Parece que los receptores centrales serían los principales implicados (29).

- Las metaloproteinasas matriz (MMP) son una familia de endopeptidasas que juegan un papel crítico en el proceso de inflamación. Liu desarrolló un estudio con la MMP-9, cuya activación en la médula espinal se relacionó con el síndrome de abstinencia inducida por opioides sin asociarse con el desarrollo de HIO (30).

- Varios estudios sugieren que, el receptor $\beta 2$-adrenérgico está relacionado con la expresión de la HIO. Chu diseñó un estudio en humanos en el cual se vio que, tras el desarrollo de HIO por remifentanilo, la administración del $\beta$-bloqueante propranolol produjo una disminución en la misma frente al control (31). Propranolol es un bloqueante tanto los receptores adrenérgicos $\beta 1$ como $\operatorname{los} \beta 2$, por lo que no se podría concluir si era el receptor adrenérgico $\beta 2$ el responsable de la HIO en el estudio.

\section{Estudios clínicos}

Distintos estudios se han realizado en los últimos tiempos para describir la expresión y la relevancia clínica de la $\mathrm{HIO}$ en humanos. Se han llevado a cabo utilizando diferentes grupos de pacientes y metodología, por lo que es difícil realizar comparaciones entre ellos (32).

\section{Ex-adictos a opioides en tratamiento de mantenimiento con metadona}

Algunos de los primeros estudios clínicos en humanos sobre la HIO pretendían describir la elevada sensibilidad al dolor que se había observado en adictos a los opioides, ya que se había objetivado que presentaban una mayor sen- sibilidad al dolor inducido por frío (cold pressor) que en voluntarios sanos (33). Sin embargo, otro tipo de estímulos como los eléctricos o de presión no provocan este efecto en los pacientes (34). Hay y cols. pretendían determinar las diferencias en la sensibilidad al dolor entre pacientes con dolor crónico en tratamiento con metadona o morfina, pacientes dependientes en tratamiento de mantenimiento con metadona y un grupo control. Los resultados indicaron que en ambos grupos de tratamiento los pacientes presentaban hiperalgesia cuando se valoraba con el test del dolor frío pero no cuando se realizaba la valoración por estimulación eléctrica (35).

\section{Exposición perioperatoria a opioides}

Un pequeño número de estudios ha evaluado la HIO producida por exposición a altas dosis de opioides en el contexto del tratamiento perioperatorio, mostrando en estos pacientes un aumento del dolor postoperatorio y un mayor consumo de opioides (34). También se ha visto que cuanto más corto es el periodo de acción de los opioides utilizados, como en el caso del remifentanilo, más rápida y frecuentemente se produce la hiperalgesia (36).

\section{Exposición aguda a opioides en voluntarios sanos}

Múltiples estudios han examinado el desarrollo de HIO en adultos sanos después de una exposición aguda a opioides usando inducción al dolor por frío, mostrando un mayor desarrollo de HIO en el grupo tratado con opioides (34). Koppert y cols. en su estudio, llegaron a la conclusión que la administración de remifentanilo conseguía disminuir la percepción del dolor (utilizando la estimulación eléctrica como estímulo doloroso) durante su administración, pero evidenciaban un aumento de la hiperalgesia al finalizar la misma (37).

Exposición prolongada a opioides en pacientes con dolor crónico

Hooten y cols., en un estudio para establecer la asociación entre la percepción del dolor inducido por calor en paciente con dolor crónico y el tratamiento con opioides, demostraron de forma significativa que aquellos pacientes con una mayor dosis equivalente de morfina presentaban un menor umbral al dolor (38).

Un estudio llevado a cabo por Wang y cols. evaluó los cambios en la sensibilidad al dolor en pacientes con dolor crónico de espalda tratados con opioides durante y posteriormente a un proceso para reducir dosis. Los pacientes fueron clasificados en 3 grupos: pacientes con dolor 
y tratamiento opioide (grupo 1), pacientes con dolor sin tratamiento opioide (grupo 2) y pacientes sin dolor ni tratamiento (grupo control) y la sensibilidad al dolor fue evaluada mediante QST. No se observaron diferencias en la sensibilidad al dolor entre el grupo 1 y el grupo 2, aunque sí hubo diferencias entre ambos grupos respecto al control, por lo que se debe seguir estudiando si es el uso crónico de opioides el causante de la hiperalgesia o si el propio dolor crónico desencadena este proceso (39). Sin embargo, otros estudios como el realizado por Suzan y cols. en 30 pacientes con dolor neuropático crónico tratados con hidromorfona y en seguimiento durante 4 semanas se observó que el tratamiento con hidromorfona producía HIO de forma dosis dependiente (40). Otro estudio en 82 pacientes sugiere que ante un estímulo doloroso con inyección subcutánea de lidocaína aquellos pacientes que tomaban opioides presentaron una mayor percepción del dolor (41). Un estudio en pacientes adictos a opioides que además presentaban dolor crónico pretendía demostrar si ese grupo de pacientes presentaba hiperalgesia. Se clasificaron los pacientes con dolor crónico en 2 grupos en función de su adicción o no a los opioides y se evaluó un tercer grupo de pacientes sin dolor ni adicción a opioides y se observó que en ambos grupos tratados con opioides el umbral de dolor fue menor que en el grupo control pero no se observaron diferencias entre el grupo de adictos y el de no adictos (42).

\section{Tratamiento}

De forma general podemos decir que la HIO puede ser tratada con una reducción en la dosis de opioides, efectuando una rotación en el opioide utilizado o asociando al tratamiento otro tipo de analgésico (43).

\section{Disminución dosis de opioides}

El principal problema de esta estrategia radica en la dificultad para su realización por las expectativas del paciente, que espera un aumento de dosis en respuesta a la exacerbación del dolor, por lo que puede encontrar el descenso de la dosis o incluso la retirada del tratamiento con opioides como una opción poco satisfactoria (44). La opción más agresiva es la desintoxicación de opioides, es decir, el abandono rápido del tratamiento con estos fármacos; existen pocas referencias en la literatura, pero en un caso reciente, esta se llevó a cabo de forma rápida manteniendo al paciente bajo anestesia general durante 5 días, consiguiendo una disminución del dolor de una puntuación basal de 7-8 en la escala EVA (escala visual analógica) hasta una puntuación de 2 y pasando el tratamiento analgésico de $100 \mathrm{mg} /$ día de morfina intravenosa a gabapentina vía oral $600 \mathrm{mg} /$ día (45).

\section{Rotación de opioides}

El cambio a otro opioide puede evitar los efectos adversos asociados al continuo incremento de la dosis del tratamiento opioide previamente instaurado. También se debe tener en cuenta que la variabilidad interindividual en el polimorfismo del receptor de morfina puede afectar la forma de unión a dicho receptor de los distintos opioides disponibles y por tanto presentar un perfil de acción y de efectos adversos variable en cada individuo (44). Es posible utilizar la rotación de opioides con una disminución de la dosis equianalgésica. A pesar de este beneficio teórico, no se ha podido demostrar el efecto de la rotación de opioides en la HIO en un ensayo clínico controlado (46).

\section{Metadona}

Sus propiedades como opioide y como antagonista del receptor NMDA hacen que el cambio a metadona o la adición de esta al tratamiento analgésico acompañada de una disminución de la dosis del tratamiento opioide de base, sea una opción verdaderamente interesante en el tratamiento de la HIO (47-49).

Es importante recordar, que la utilización de metadona se ha asociado con incremento de dolor en estudios observacionales en adictos a opioides en tratamiento con este fármaco.

Por este motivo, el cambio del tratamiento opioide a metadona debe realizarse teniendo en cuenta que puede presentar activación de vías pro-nociceptivas en lugar de sus propiedades como antagonista del receptor NMDA (32) y sin olvidar otra serie de efectos adversos o la toxicidad asociada que conlleva su uso, siendo de especial importancia la vigilancia de signos como las Torsade de Pointes en caso de utilizar altas dosis (34). El uso de metadona a dosis relativamente bajas (<30 mg/día) es efectivo en el tratamiento crónico del dolor. Un estudio retrospectivo en el que se revisaron las historias de 240 pacientes, observó que la administración de metadona a dosis bajas conseguía excelentes resultados en el control del dolor y en la HIO (47). Sin embargo la utilización de dosis altas puede desarrollar hiperalgesia (31).

\section{Antagonistas del receptor NMDA}

A pesar de que el mecanismo por el que se produce la HIO no está totalmente definido, se ha observado en modelos preclínicos la implicación del sistema glutamatérgico y una activación patológica del receptor del NMDA. Por tanto, muchos estudios en el tratamiento de la HIO se han centrado en la modulación del sistema glutamatérgico a través del receptor de NMDA (32). 
Ketamina

Es un anestésico disociativo desarrollado para su uso clínico en la década de los 60 , pero debido a su actividad como inhibidor competitivo del sitio de unión de la fenciclidina en el receptor del NMDA se ha estudiado su uso a dosis subanestésicas para intentar disminuir la HIO (32). A pesar de que en estudios experimentales la ketamina ha mostrado una reducción en la hiperalgesia, los ensayos clínicos han encontrado resultados contradictorios.

Una revisión de 11 ensayos aleatorizados en los que se añadía ketamina al tratamiento opioide para el dolor postoperatorio, se observó que en 6 de dichos ensayos la analgesia postoperatoria se veía mejorada con la adición de ketamina. Sin embargo, en otros 5 estudios no se observaba ningún beneficio clínico. En cirugía torácica la combinación de ketamina con el tratamiento opioide demostró una reducción significativa en la escala del dolor y en la dosis de opioide consumida, mientras que en cirugía ortopédica o abdominal este efecto no se confirmó (50).

Otro ensayo en 40 pacientes estudió los efectos de dosis bajas de ketamina administrada durante la cirugía sobre la hiperalgesia inducida por remifentanilo en pacientes ginecológicas anestesiadas con sevofluorano. Se demostró que el dolor postoperatorio y la demanda de morfina fue significativamente menor en el grupo tratado con ketamina en las 2 y 3 horas posteriores a la cirugía (36).

En resumen, el uso de ketamina tanto durante una cirugía o de forma postoperatoria puede disminuir los requerimientos de opioides y ayudar a prevenir la HIO producida por una exposición a dosis elevadas de opioides durante una cirugía (51).

En un estudio de 15 pacientes con dolor crónico en tratamiento con opioides que habían desarrollado tolerancia y probable HIO, se administró una infusión de ketamina a dosis subanestésicas para ayudar a una retirada completa del tratamiento opioide. Los resultados obtenido a los 6 meses destacan que la infusión de ketamina fue bien tolerada por la mayoría; en el mes siguiente a la infusión la mayor parte de los pacientes mostró una disminución en su nivel de dolor pero únicamente 3 pacientes referían encontrarse mejor y no recibían tratamiento opioide (52).

\section{Dextrometorfano}

Usado como antitusivo, presenta actividad como antagonista no competitivo del receptor NMDA (34). A pesar de que se ha estudiado de forma indirecta en numerosos estudios su capacidad de atenuar o prevenir la HIO, no se ha conseguido demostrar su eficacia (44).

En un estudio de 829 pacientes con dolor crónico no debido al cáncer, se comparó la administración de una combinación de dextrometorfano y morfina frente a la administración de morfina sin observarse diferencias en la aparición de HIO entre ambos grupos (32).

\section{Sulfato de magnesio}

El magnesio es un antagonista el receptor NMDA, bloquea la entrada de calcio a través del receptor consiguiendo inhibir la despolarización que conduce al impulso nociceptivo. Debido a esto el bloqueo del receptor NMDA en el periodo perioperatorio por el magnesio puede tener un papel importante en el control del dolor postoperatorio y en la HIO.

En el estudio de Lee y cols. 75 pacientes sometidos a una prostatectomía laparoscópica, fueron divididos en 3 grupos: grupo M (tratado con una infiltración con sulfato magnésico y remifentanilo a dosis bajas), grupo $\mathrm{S}$ (tratado únicamente con remifentanilo a dosis altas) y grupo $\mathrm{D}$ (tratado únicamente con desfluorano). Se determinó que los pacientes de los grupos M y D presentaron menor dolor, mayor tiempo hasta la petición de analgesia y menor dosis de analgesia en el postoperatorio (53).

\section{Otros antagonistas del receptor de NMDA}

Las generaciones siguientes de antagonistas del receptor de NMDA presentan una menor afinidad por el receptor por lo que permiten la apertura del canal de una forma más rápida evitando así interferencias en la transmisión sináptica. El prototipo de fármaco con estas propiedades es la memantina, que en estudios de modelos animales ha mostrado reducir la hiperalgesia (32).

\section{Propofol}

Se ha sugerido que el propofol podría modular la HIO, debido a sus propiedades como análogo del ácido gammaaminobutírico (GABA) y a su actividad en sus receptores a nivel supraespinal. Los efectos del propofol a dosis subhipnóticas en la hiperalgesia inducida por remifentanilo se evaluaron en un estudio en voluntarios sanos, observándose en el grupo tratado con propofol una HIO de aparición tardía y más débil (54). Sin embargo, existe controversia en cuanto a los efectos analgésicos del propofol; el estudio de Wang y cols. realizado en ratas, muestra que los efectos mediados a través del receptor del GABA ${ }_{\mathrm{A}}$ pueden generar hiperalgesia inducida por propofol (55).

\section{Gabapentina}

Es un análogo del GABA, desarrollado en un primer momento como fármaco antiepiléptico pero sus propieda- 
des como analgésico en el tratamiento del dolor neuropático hacen que actualmente esté considerado un medicamento de primera línea en el tratamiento de este tipo de dolor (51). Este efecto sobre el dolor neuropático se atribuye a la capacidad de la gabapentina de provocar la hiperpolarización en las neuronas por activar canales calcio dependientes (56).

Según el estudio de Van Elstraete y cols. en el que se valoró la efectividad de la gabapentina en la prevención de la hiperalgesia inducida por fentanilo en ratas, este medicamento administrado intratecal o intraperitonealmente, prevenía la aparición del descenso del umbral del dolor de manera dosis dependiente; mostrando que previene el desarrollo de hiperalgesia inducida por una exposición aguda a opioides. En estudio también se determinó que este mecanismo está en parte relacionado con la activación de la subunidad $\alpha_{2} \delta$ de los canales de calcio voltaje dependientes (57).

En otro estudio reciente, en pacientes adictos en tratamiento de mantenimiento con metadona, donde se evaluaba la eficacia de la gabapentina para revertir la HIO instaurada en estos pacientes, se observó en el grupo tratado con gabapentina un incremento estadísticamente significativo en el umbral del dolor y en la tolerancia a este (56).

\section{Inhibidores de la ciclooxigenasa (COX)}

Las prostaglandinas pueden modular las rutas nociceptivas produciendo la liberación de glutamato (aminoácido excitatorio). Por otro lado, los inhibidores de la COX han mostrado actividad como antagonista del receptor NMDA; por todo esto, se piensa que la inhibición de la síntesis de prostaglandinas a nivel de la médula espinal podría atenuar o impedir la aparición de HIO modulada por el receptor NMDA (34). Este efecto se ha asociado con los inhibidores de la COX-2. Sin embargo, se ha demostrado que la administración de parecoxib antes de la exposición al opioide no puede revertir una HIO ya instaurada. Este hecho sugiere que aunque los mecanismos por los que se produce la HIO estén modulados por la actividad anti-COX-2, su papel es menos importante que el de los receptores NMDA (32). En otros estudios con inhibidores de la COX, se han visto como posibles moduladores de la $\mathrm{HIO}$ otros fármacos como ibuprofeno, ketorolaco o lornoxicam $(58,59)$.

\section{$\alpha 2$-agonistas}

Algunos estudios han intentado determinar el papel de los agonistas del receptor $\alpha 2$-adrenérgico en la modulación de la HIO. Koppert y cols. en un intento para determinar los mecanismos por los que se produce la HIO, estudiaron los efectos de la administración conjunta de remifentanilo y clonidina observándose una disminución significativa en la hiperalgesia al compararlo con remifentanilo solo (37). Por otro lado, en una serie de 11 casos con HIO producida por el tratamiento crónico con opioides, se consiguió mejorar el control del dolor y disminuir la dosis de opioides utilizada al tratar a los pacientes con dexmedetomidina (60). La dexmedetomidina es agonista selectivo de los receptores $\alpha 2$-adrenérgicos, usado principalmente para sedación de corta duración en pacientes sometidos a ventilación mecánica y se ha mostrado que su administración sistémica potencia el efecto analgésico de los opioides y reduce el consumo de estos en el periodo perioperatorio (61). La actividad de la dexmedetomidina como modulador de la HIO puede estar mediada por la capacidad de los agonistas $\alpha 2$-adrenérgicos de regular la actividad sináptica en la médula espinal mediada por los receptores NMDA. Zheng y cols. en su estudio para evaluar la eficacia de la dexmedetomidina en la hiperalgesia inducida por remifentanilo en ratones, demostraron que en el grupo tratado con dexmedetomidina se reducía de forma significativa la HIO y la alodinia (61).

\section{Buprenorfina}

La buprenorfina es un opioide con propiedades de agonista parcial en receptores $\mu$, con efecto variable sobre los receptores $\kappa$ y con propiedades antagónicas con el receptor $\delta$ (62). También es capaz de activar los receptores del ligando endógeno nociceptina/orfanina FQ, es decir, los "opioid-like receptor" (ORL) (63). La activación a nivel dorsal de la médula espinal tiene efectos analgésicos, sin embargo, su activación supraespinal provocaría un efecto nociceptivo. Por lo tanto, la activación a nivel espinal de estos receptores por la buprenorfina podría resultar en una reducción del dolor neuropático y al mismo tiempo en hiperalgesia debido a la modulación de los canales de calcio que están estrechamente relacionados con dicho receptor (64). En un estudio realizado en 2013, se evaluó el efecto antihiperalgésico de la buprenorfina en ratas con una neuropatía inducida demostrando que dosis bajas de buprenorfina provocaban una potente supresión de la neuropatía hiperalgésica (63). Otro estudio comparativo entre fentanilo y buprenorfina administrados por vía percutánea en voluntarios sanos a los que se les inducía un proceso de hiperalgesia, únicamente buprenorfina demostró un efecto contrario a la hiperalgesia inducida (62).

\section{Estrategias terapéuticas}

Aunque son varias las opciones terapéuticas que se presentan a la hora de tratar un paciente con HIO, algunas revisiones proponen un algoritmo de ayuda al diagnóstico y 
tratamiento de la $\mathrm{HIO}$ que puede resumirse en los siguientes puntos (34):

- Aumentar la dosis de opioides y evaluar si existe un aumento de la eficacia. De esta manera conseguiremos descartar que el paciente presente un cuadro de tolerancia.

- Reducir o eliminar los opioides y evaluar la HIO.

- Utilizar aquellos opioides que por sus propiedades puedan disminuir o mitigar la $\mathrm{HIO}$, como son la metadona o la buprenorfina.

- Utilizar un antagonista específico del receptor de NMDA.

- Proporcionar una terapia combinada con inhibidores de la COX-2.

\section{CONCLUSIÓN}

La HIO es un fenómeno bien establecido en modelos animales, siendo cada vez más estudiada en pacientes que reciben tratamiento con opioides.

La HIO se puede interpretar de manera errónea como tolerancia, un fenómeno relacionado pero distinto. Así como la tolerancia se resuelve con un aumento de dosis de opioides, la HIO lo haría con una disminución de dosis de los mismos.

Los mecanismos por los que se desarrolla la HIO siguen siendo confusos y parecen estar relacionados con la influencia excitatoria de los receptores NMDA y con el aumento de la sensibilidad a los estímulos nociceptivos, pudiendo estar todos ellos interrelacionados e influenciados por determinantes genéticos.

Aunque parece ser más común en pacientes que reciben opioides de manera crónica, HIO ha sido observada con dosis muy bajas y con la administración aguda de opioides a dosis elevadas. Tampoco se puede concluir que determinados opioides estén más asociados que otros ya que son pocos los ensayos clínicos con humanos y difieren en el modo de empleo y cantidad de opioide administrado.

Actualmente no están claros los factores de riesgo para desarrollar HIO, por lo que se requieren estudios futuros, más aún cuando este fenómeno se ha asociado a un consumo crónico de opioides cada día más en auge.

El consumo racional de esta familia de fármacos es fundamental para que sigan representando uno de los tratamientos más eficaces en el control del dolor, tanto crónico como agudo.

\section{CORRESPONDENCIA:}

Ángela Gil Martín

Servicio de Farmacia

Hospital Universitario de Getafe

Carretera de Toledo, $\mathrm{km} 12,500$

28905 Getafe, Madrid

e-mail: angela.gil@salud.madrid.org

\section{BIBLIOGRAFÍA}

1. Chapman CR, Lipschitz DL, Angst MS, Chou R, Denisco $\mathrm{RC}$, Donaldson GW, et al. Opioid pharmacotherapy for chronic non-cancer pain in the United States: A research guideline for developing an evidence-base. J Pain 2010;11(9):80729.

2. Català E, Ferrándiz M, Lorente L, Landaluce Z, Genové M. Uso de opioides en el tratamiento del dolor crónico no oncológico. Recomendaciones basadas en las guías de práctica clínica. Rev Esp Anestesiol Reanim 2011;58(5):283-9.

3. Manchikanti L, Fellows B, Ailinani H, Pampati V. Therapeutic use, abuse, and nonmedical use of opioids: A ten-year perspective. Pain Physician 2010;13(5):401-35.

4. Azevedo LF, Costa-Pereira A, Mendonça L, Dias CC, Castro-Lopes JM. A population-based study on chronic pain and the use of opioids in Portugal. Pain 2013;154(12):2844-52.

5. Ballantyne JC, Shin NS. Efficacy of opioids for chronic pain: A review of the evidence. Clin J Pain 2008;24(6):46978.

6. Saper JR, Lake AE 3rd, Bain PA, Stillman MJ, Rothrock JF, Mathew NT, et al. A practice guide for continuous opioid therapy for refractory daily headache: Patient selection, physician requirements, and treatment monitoring. Headache 2010;50(7):1175-93.

7. Manchikanti L, Manchikanti KN, Pampati V, Cash KA. Prevalence of side effects of prolonged low or moderate dose opioid therapy with concomitant benzodiazepine and/ or antidepressant therapy in chronic non-cancer pain. Pain Physician 2009;12(1):259-67.

8. Benyamin R, Trescot AM, Datta S, Buenaventura R, Adlaka R, Sehgal N, et al. Opioid complications and side effects. Pain Physician 2008; 11(2 Supl.): S105-20.

9. Richebé P, Beaulieu P. Perioperative pain management in the patient treated with opioids: Continuing professional development. Can J Anaesth 2009;56(12):969-81.

10. Albutt C. On the abuse of hypodermic injections of morphia. Practitioner 1870;5:327-31.

11. Holtman JR Jr, Jellish WS. Opioid-induced hyperalgesia and burn pain. J Burn Care Res 2012;33(6):692-701.

12. Johnson JL, Hutchinson MR, Williams DB, Rolan P. Medication-overuse headache and opioid-induced hyperalgesia: A review of mechanisms, a neuroimmune hypothesis and a novel approach to treatment. Cephalalgia 2013;33(1):52-64.

13. Sng BL, Schug SA. The role of opioids in managing chronic non-cancer pain. Ann Acad Med Singapore 2009;38(11):960-6.

14. Lee SH, Cho SY, Lee HG, Choi JI, Yoon MH, Kim WM. Tramadol induced paradoxical hyperalgesia. Pain Physician 2013;16(1):41-4.

15. Zylicz Z, Twycross R. Opioid-induced hyperalgesia may be more frequent than previously thought. J Clin Oncol 2008;26(9):1564.

16. Chen Y, Yang C, Wang ZJ. CAMKII is required for the initiation and maintenance of opioid-induced hyperalgesia. J Neurosci 2010;30(1):38-46.

17. Zhao M, Joo DT. Enhancement of spinal N-methyl-Daspartate receptor function by remifentanil action at -opioid receptors as a mechanism for acute opioid-induced hyperalgesia or tolerance. Anesthesiology 2008;109(2):308-17.

18. Ram K, Eisenberg E, Haddad M, Pud D. Oral opioid use alters DNIC but not cold pain perception in patients with chronic pain - New perspective of opioid-induced hyperalgesia. Pain 2009;139(2):431-8. 
19. Zhao Y, Chen S, Chen H, Pan H. Chronic opioid potentiates presynaptic but impairs postsynaptic N-Methyl-Daspartic acid receptor activity in spinal cords. J Biol Chem 2012;287(30):25073-85.

20. Goldberg J. Chronic opioid therapy and opioid tolerance: A new hypothesis. Pain Research and Treatment 2013;2013:407504.

21. Chen Y, Geis C, Sommer C. Activation of TRPV1 contributes to morphine tolerance: Involvement of the mitogenactivated protein kinase signaling pathway. J Neurosci 2008;28(22):5836-45.

22. Hogan D, Baker A, Morón J, Carlton S. Systemic morphine treatment induces changes in firing patterns and responses of nociceptive afferent fibers in mouse glabrous skin. Pain 2013;154(11):2297-309.

23. Vardanyan A, Wang R, Vanderah T, Ossipov M, Lai J, Porreca F, et al. TRPV1 receptor in expression of opioid-induced hyperalgesia. J Pain 2009;10(3):243-52.

24. Wilson N, Jung H, Ripsch M, Miller R, White F. CXCR4 signaling mediates morphine-induced tactile hyperalgesia. Brain Behav Immun 2011;25(3):565-73.

25. Liang D, Shi X, Qiao Y, Angst MS, Yeomans DC, Clark JD. Chronic morphine administration enhances nociceptive sensitivity and local cytokine production after incision. Mol Pain 2008;4:7.

26. Heinl C, Drdla-Schutting R, Xanthos N, Sandkühler J. Distinct mechanisms underlying pronociceptive effects of opioids. J Neurosci 2011;31(46):16748-56.

27. Liang D, Li X, Clark D. Epigenetic regulation of opioidinduced hyperalgesia, dependence, and tolerence in mice. J Pain 2013;14(1):36-47.

28. Waxman A, Arout C, Caldwell M, Dahan A, Benjamin K. Acute and chronic fentanyl administration causes hyperalgesia independently of opioid receptor activity in mice. Neurosci Lett 2009;462(1):68-72.

29. Liang D, Li X, Clark D. 5-Hydroxytryptamine type 3 receptor modulates opioid-induced hyperalgeisa and tolerance in mice. Anesthesiology 2011;114(5):1180-9.

30. Liu Y, Berta T, Liu T, Tan P, Ji R. Acute morphine induces matrix metalloproteinase-9 up-regulation in primary sensory neurons to mask opioide-induced analgesia in mice. Mol Pain 2012;8:19.

31. Chu L, Cun T, Ngai L, Kim J, Zamora A, Young C, et al. Modulation of remifentanil-induced postinfusion hyperalgesia by the -blocker propranolol in humans. Pain 2012;153(5):974-81.

32. Chu LF, Angst MS, Clark D. Opioid-induced hyperalgesia in humans: Molecular mechanisms and clinical considerations. Clin J Pain 2008;24(6):479-96.

33. Raffa RB, Pergolizzi JV Jr. Opioid-induced hyperalgesia: Is it clinically relevant for the treatment of pain patients? Pain Manag Nurs 2013;14(3):e67-83.

34. Lee M, Silverman SM, Hansen H, Patel VB, Manchikanti L. A comprehensive review of opioid-induced hyperalgesia. Pain Physician 2011;14(2):145-61.

35. Hay JL, White JM, Bochner F, Somogyi AA, Semple TJ, Rounsefell B. Hyperalgesia in opioid-managed chronic pain and opioid-dependent patients. J Pain 2009;10(3):316-22.

36. Hong BH, Lee WY, Kim YH, Yoon SH, Lee WH. Effects of intraoperative low dose ketamine on remifentanil-induced hyperalgesia in gynecologic surgery with sevoflurane anesthesia. Korean J Anesthesiol 2011;61(3):238-43.

37. Koppert W, Sittl R, Scheuber K, Alsheimer M, Schmelz M, Schüttler J. Differential modulation of remifentanil-induced analgesia and postinfusion hyperalgesia by S-ketamine and clonidine in humans. Anesthesiology 2003;99(1):152-9.

38. Hooten WM, Mantilla CB, Sandroni P, Townsend CO. Associations between heat pain perception and opioid dose among patients with chronic pain undergoing opioid tapering. Pain Med 2010;11(11):1587-98.

39. Wang H, Akbar M, Weinsheimer N, Gantz S, Schiltenwolf M. Longitudinal observation of changes in pain sensitivity during opioid tapering in patients with chronic low-back pain. Pain Med 2011;12(12):1720-6.

40. Suzan E, Eisenberg E, Treister R, Haddad M, Pud D. A negative correlation between hyperalgesia and analgesia in patients with chronic radicular pain: Is hydromorphone therapy a double-edged sword? Pain Physician 2013;16(1):6576.

41. Kim SH, Yoon DM, Choi KW, Yoon KB. High-dose daily opioid administration and poor functional status intensify local anesthetic injection pain in cancer patients. Pain Physician 2013;16(3):E247-56.

42. Fishbain DA, Lewis JE, Gao J. Are psychoactive substance (opioid)-dependent chronic pain patients hyperalgesic? Pain Pract 2011;11(4):337-43.

43. Leal Pda C, Clivatti J, Garcia JB, Sakata RK. Opioid-induced hiperalgesia. Rev Bras Anestesiol 2010;60(6):63947,355-9.

44. Brush DE. Complications of long-term opioid therapy for management of chronic pain: The paradox of opioid-induced hyperalgesia. J Med Toxicol 2012;8:387-92.

45. Siniscalchi A, Piraccini E, Miklosova Z, Taddei S, Faenza S, Martinelli G. Opioid-induced hyperalgesia and rapid opioid detoxification after tacrolimus administration. Anesth Analg 2008;106(2):645-6.

46. Tompkins DA, Campbell CM. Opioid-induced hyperalgesia: Clinically relevant or extraneous research phenomenon? Curr Pain Headache Rep 2011;15(2):129-36.

47. Salpeter SR, Buckley JS, Bruera E. The use of very-lowdose methadone for palliative pain control and the prevention of opioid hyperalgesia. J Palliat Med 2013;16(6):61622.

48. Centeno Cortés C, Olier Gárate C. Hyperalgesia in patients treated with opioids with cancer pain. Med Clin (Barc) 2009;133(18):725-6.

49. Vorobeychik Y, Chen L, Bush MC, Mao J. Improved opioid analgesic effect following opioid dose reduction. Pain Med 2008;9(6):724-7.

50. Carstensen M, Møller AM. Adding ketamine to morphine for intravenous patient-controlled analgesia for acute postoperative pain: A qualitative review of randomized trials. $\mathrm{Br}$ J Anaesth 2010;104(4):401-6.

51. Weinbroum AA. Non-opioid IV adjuvants in the perioperative period: Pharmacological and clinical aspects of ketamine and gabapentinoids. Pharmacol Res 2012;65(4):411-29.

52. Quinlan J. The use of a subanesthetic infusion of intravenous ketamine to allow withdrawal of medically prescribed opioi$\mathrm{ds}$ in people with chronic pain, opioid tolerance and hyperalgesia: Outcome at 6 months. Pain Med 2012;13(11):1524-5.

53. Lee C, Song YK, Jeong HM, Park SN. The effects of magnesium sulfate infiltration on perioperative opioid consumption and opioid-induced hyperalgesia in patients undergoing robot-assisted laparoscopic prostatectomy with remifentanilbased anesthesia. Korean J Anesthesiol 2011;61(3):244-50.

54. Singler B, Tröster A, Manering N, Schüttler J, Koppert W. Modulation of remifentanil-induced postinfusion hyperalgesia by propofol. Anesth Analg 2007;104(6):1397-403. 
55. Wang QY, Cao JL, Zeng YM, Dai TJ. GABAA receptor partially mediated propofol-induced hyperalgesia at superspinal level and analgesia at spinal cord level in rats. Acta Pharmacol Sin 2004;25(12):1619-25.

56. Compton P, Kehoe P, Sinha K, Torrington MA, Ling W. Gabapentin improves cold-pressor pain responses in methadone-maintained patients. Drug Alcohol Depend 2010;109(1-3):213-9.

57. Van Elstraete AC, Sitbon P, Mazoit JX, Benhamou D. Gabapentin prevents delayed and long-lasting hyperalgesia induced by fentanyl in rats. Anesthesiology 2008;108(3):484-94.

58. Xuerong Y, Yuguang H, Xia J, Hailan W. Ketamine and lornoxicam for preventing a fentanyl-induced increase in postoperative morphine requirement. Anesth Analg 2008;107(6):2032-7.

59. Akbari E. The role of cyclo-oxygenase inhibitors in attenuating opioid-induced tolerance, hyperalgesia, and dependence. Med Hypotheses 2012;78(1):102-6.
60. Belgrade M, Hall S. Dexmedetomidine infusion for the management of opioid-induced hyperalgesia. Pain Med 2010;11(12):1819-26.

61. Zheng Y, Cui S, Liu Y, Zhang J, Zhang W, Zhang J, et al. Dexmedetomidine prevents remifentanil-induced postoperative hyperalgesia and decreases spinal tyrosine phosphorylation of N-methyl-d-aspartate receptor 2B subunit. Brain Res Bull 2012;87(4-5):427-31.

62. Andresen T, Staahl C, Oksche A, Mansikka H, ArendtNielsen L, Drewes AM. Effect of transdermal opioids in experimentally induced superficial, deep and hyperalgesic pain. Br J Pharmacol 2011;164(3):934-45.

63. Takahashi T, Okubo K, Kojima S, Nishikawa H, Takemura M, Tsubota-Matsunami M, et al. Antihyperalgesic effect of buprenorphine involves nociceptin/orphanin FQ peptidereceptor activation in rats with spinal nerve injury-induced neuropathy. J Pharmacol Sci 2013;122(1):51-4.

64. Induru RR, Davis MP. Buprenorphine for neuropathic pain - targeting hyperalgesia. Am J Hosp Palliat Care 2009;26(6):470-3. 